\title{
Putting policy into practice? Poverty and people with serious mental illness
}

\author{
Robert Wilton* \\ School of Geography and Geology, McMaster University, 1280 Main Street West, Hamilton, ON, Canada 18S 4 M1
}

\begin{abstract}
This paper addresses the effects of chronic poverty on people with serious mental illness. More specifically, we are concerned with the extent to which welfare restructuring, by deepening the poverty facing people with serious mental illness, undermines the expressed intent of mental health policy to improve the quality of life (QOL) of this population. The province of Ontario in Canada forms the setting for the study. The paper first examines recent trends in mental health care and social assistance policy in Ontario. While income support is consistently recognized as a core element of mental health care, welfare restructuring has led to a significant decline in the real value of income supports received by people with serious mental illness. The paper then examines the implications of this trend for the QOL of residential care facility tenants in Hamilton, Ontario. Here, the case study is explicitly connected to QOL scholarship. In addition, the study is grounded in an analysis of the broader transformation of the welfare state in Ontario. Interview data suggest that tenants experience chronic poverty that has a deleterious impact on multiple life domains including basic needs, family, social relations, leisure and self-esteem. Implications for research and policy are discussed.
\end{abstract}

(C) 2003 Elsevier Science Ltd. All rights reserved.

Keywords: Mental illness; Poverty; Quality of life; Welfare restructuring; Residential care facilities; Canada

\section{Introduction}

In recent decades, an overriding emphasis in the mental health policy of many Western countries has been the continuing movement away from the provision of institutional care to community-based programs for people with serious mental illness ${ }^{1}$ (Dear \& Wolch, 1987; Dickinson, 2001; Goldman, 1999; Nelson, Lord, \& Ochocka, 2001; Rosenheck, 1999). During the same period, there have also been significant changes in the provision of social welfare that hold implications for people with serious mental illness living in community

\footnotetext{
*Tel.: + 1-905-525-9140; fax: + 1-905-546-0463.

E-mail address: wiltonr@mcmaster.ca (R. Wilton).

${ }^{1}$ Serious mental illness refers to diagnoses of schizophrenia, major affective disorder or personality disorder, which are disabling and of a long duration (Ontario Ministry of Health, 1998). Diagnoses that predominate are schizophrenia, major affective disorders, organic brain syndrome, and paranoid and other psychoses (Ontario Ministry of Health, 1998).
}

settings. Countries such as Canada, the UK and the US have witnessed what Peck (2001) terms a series of bold experiments and seismic shifts away from traditional welfare states toward 'workfare' programs that impose mandatory work requirements for people who receive benefits (also Evans, 2002; Handler \& Hasenfeld, 1997). At the same time, welfare rates have often been frozen or reduced and time limits for assistance introduced, with the justification that these strategies provide added incentive for people to escape 'welfare dependency' (Russell, 1998). These changes are part of a broader transformation away from the postwar universal welfare state toward the selective provision of social welfare to address 'real needs' (Langan, 1998).

While persons with recognized disabilities who satisfy specific criteria are often able to access additional supports and are exempted from workfare requirements, welfare restructuring has had important implications for people with disabilities (Batavia \& Beaulaurier, 2001). Rosenheck (1999) argues that reductions in welfare 
programs have made 'community survival' increasingly difficult for people with serious mental illness in particular (also Goldman, 1999; Nelson et al., 2001). More generally, relative and absolute declines in social assistance, more stringent application procedures, and a focus on individual responsibility and accountability contribute to growing precariousness in the daily lives of many disabled people. Within the context of ongoing changes, people with serious mental illness continue to face multiple challenges to full participation in social life (Capponi, 1992; Carne, 1998; Wilson, 1996). In addition to the challenges posed by mental illness, people face structural barriers such as poverty, social stigma, a lack of affordable housing and limited employment opportunities (Boydell, Gladstone, Crawford, \& Trainor, 1999; Wahl, 1999; Ware and Goldfinger, 1997).

The purpose of this paper is to examine the implications of these ongoing developments in mental health care and social assistance for people with serious mental illness living in community settings. More specifically, the paper is concerned with the extent to which welfare restructuring, by deepening the poverty facing people with serious mental illness, is undermining the expressed intent of mental health care policy to improve the quality of life (QOL) of this population.

After a review of the literatures on poverty and QOL for people with serious mental illness, the paper first examines recent trends in mental health and social (welfare) assistance policy in the province of Ontario with particular attention given to the issue of income support. The paper then compares and contrasts the expressed intent of recent policy with the lived experiences of people with serious mental illness using a qualitative study of residential care facilities tenants in Hamilton, Ontario. In so doing, the paper contributes to an understanding of the impact of poverty on the QOL of people with serious mental illness.

\section{Poverty}

Poverty means having insufficient money, goods or means of support. The precise definition of the term varies between different contexts (Lott \& Bullock, 2001). In Canada, poverty is determined by Statistics Canada's "Low-Income Cut-Offs" (LICO). LICOs vary depending upon family and settlement size, but in general terms, people are considered to poor if they spend more than $56.2 \%$ of gross income on food, clothing and shelter (Chappell, 2000). However, official definitions say little about the manifold effects of poverty on people's daily lives. Poverty has profoundly negative implications for physical and mental health, self-esteem, education, political participation, diet, safety, housing, friendships and family life (e.g., Advisory Committee on Population Health, 1999; Lott \& Bullock, 2001).
As a population, people with mental illnesses are heavily concentrated among society's poor. In Canada, almost $27 \%$ of adults with mental illness were living in poverty in 1991 , compared with $12.6 \%$ of non-disabled people, and the figure for people with serious mental illness is undoubtedly much higher (Capponi, 1997; Fawcett, 1996). While there has been considerable research on poverty and mental health, much of it concerns socioeconomic status as a causal factor in the development of mental ill health (Cohen, 2000a; Saraceno \& Barbui, 1997; Shore, 1997). Recent work has begun to examine the effects of poverty on community living and the mental health of consumers. Studies show that poverty effects people's ability to find decent housing in safe neighborhoods (Carling \& Curtis, 1997; Newman, 1994). There is some evidence to suggest that poverty negatively impacts opportunities to develop social networks (Hannum et al., 1994). Nelson et al. (2001) argue that a lack of material resources works against consumer empowerment, while Kearns (1990) found consumer satisfaction with community life significantly correlated with income (also UK700 Group, 1999). Some scholars argue that economic marginalization faced by consumers is a form of social oppression (Lord \& Dufort, 1996), and others contend that material deprivation poses a greater challenge than mental illness (Lurigio \& Lewis, 1989).

Existing studies also identify several avenues for further research. Cohen (1993) called for research that gives serious consideration to the social context to examine the different ways in which class/poverty and psychiatric illness intersect, a call echoed by Draine, Salzer, Culhane, \& Hadley (2002) and Boydell et al. (1999). Several studies argue for research on strategies people use to cope with poverty, and the impact of those strategies on their mental health (Estroff, Zimmer, Lachiotte, Benoit, \& Patrick, 1996; Ware \& Goldfinger, 1997; Kelly, McKenna, Parahoo, \& DuSoir, 2001). Other scholars argue that a focus on material resources is needed to counter a continuing tendency to explain barriers to social participation in medical terms (Thoits, 1995; Cohen, 2000a; Yanos, Rosenfield, \& Horwitz, 2001).

\section{Measuring $Q O L$}

QOL can be understood conceptually to encompass three broad dimensions: what an individual is capable of doing (functional status); access to resources and opportunities, and a sense of well-being (Lehman, 1999). As these broad dimensions imply, QOL comprises both objective and a subjective elements (Atkinson \& Zibin, 1996). In addition, more specific topical areas or 'life domains' can be identified, including health, family, social relations, and living situation. In recent decades, a number of instruments have been designed specifically to 
measure the objective and/or subjective dimensions of QOL for people with serious mental illness (e.g., Bigelow, Gareau, \& Young, 1990; Huxley \& Warner, 1992; Lehman, 1983; Oliver, 1992). In a review of twenty-eight instruments, the five most frequently utilized 'life domains' were: health, self esteem/wellbeing, community/productivity, social/love relationships, and leisure/creativity (Atkinson \& Zibin, 1996). Other domains, including family, living situation and finances appeared less frequently. As Atkinson and Zibin (1996, p. 5) note, the infrequent use of these categories was unexpected: "given the dependence of chronic populations on financial and material support from both families and the larger society." Of particular relevance for this paper is the fact that fewer than half of the instruments included items concerning finances.

The relative absence of income measures from existing QOL instruments hinders an understanding of the role of poverty in the daily lives of people living with serious mental illness. ${ }^{2}$ It also signals a continuing disconnect between the research priorities of at least some mental health professionals, and priorities identified by mental health consumers themselves that include "the effects of society, poverty and racial discrimination" (Cohen, 2000b, p. 937). Without the inclusion of objective and subjective financial measures, it is difficult to understand the significance of the income people have, or their feelings about the adequacy of that income, for overall QOL.

This paper is concerned with an exploration of the ways in which poverty impacts multiple 'life domains' of people with serious mental illness in community settings. Existing studies link poverty to the difficulties people with serious mental illness experience when attempting to access decent housing, to build social networks, and more generally to diminished consumer empowerment and satisfaction with community life. Considering the range of 'life domains' typically identified in QOL instruments, it is not unreasonable to suggest that, in addition to a direct impact on objective and subjective finance measures, poverty may also influence many, if not most, of these domains including leisure activities, social relations, family, self-esteem, community, and living situation.

The intent of this paper is not to suggest that poverty is the sole cause of difficulties people with serious mental illness face in the community, but rather to argue that it is essential to further explore the interrelationships between poverty and QOL within the context of daily life. This exploration is important for both research and policy. In research terms, recent studies argue that

\footnotetext{
${ }^{2}$ In those instruments that do include financial status it frequently emerges as a significant indicator of QOL (e.g., Lehman, 1983; Oliver, 1992; Trauer, Duckmanton, \& Chiu, 1998).
}

efforts to improve QOL among people with serious mental illness need to recognize the complex interrelationships between a wide variety of demographic, clinical and social variables (Lam \& Rosenheck, 2000; UK700 Group, 1999), but there remains a tendency to trivialize the social environment (Cohen, 2000a). In policy terms, a better understanding of the links between poverty and QOL is urgent given the magnitude of ongoing changes to social welfare and mental health care in Canada and other contexts.

\section{Research questions}

From the preceding discussion, it is possible to identify two specific research questions. First, to what extent have recent developments in the policy and provision of mental health care and social assistance in Ontario recognized and addressed the poverty experienced by persons with serious mental illness living in community settings? Second, in what ways does poverty impact on multiple 'life domains' (e.g., basic needs, social relations, family, leisure activities, self-esteem) that contribute to the QOL experienced by people with serious mental illness?

\section{Mental health policy and welfare reform in Ontario}

Ontario's mental health care and social assistance systems have witnessed substantial change in the past 15 years, driven in part by broader trends in the political economy of the province. For mental health care, key policy documents spanning the period 1988-2001 were examined for reference to the larger goals of mental health care system and for specific reference to income support as part of comprehensive response to the needs of people with serious mental illness. For social assistance, attention was focused on developments between 1995 and 2001 as this period saw the introduction of new 'workfare' and disability support programs.

\section{Mental health policy}

Three key mental health policy documents have been issued in Ontario in the past 15 years by three different governments, each concerned with comprehensive reform in mental health care. In 1988, the Liberal government released Building Community Support for People. The document and the consultations that informed it are seen as marking a significant break in mental health policy (Everett, 2000). Nelson et al. (2001, p. 78) argue that this was the first time consumers and their families: 'were given a voice in what they wanted in mental health policy in Ontario.' In the report, explicit commitment is made to a mental health system focused in the community, with emphasis placed on services such 
as crisis and residential support, case management, selfhelp and family support, and social/vocational support.

For the purposes of this paper it is notable that attention is given to income as an essential component of the mental health system. Identifying goals for comprehensive mental health care, the report states that the province should: 'provide access to adequate incomes through work or social assistance' and 'enhance QOL as well as quality of care' (Ontario Ministry of Health, 1988, p. 6). The report also draws explicitly on population health research $(1988$, p. 16). The population health perspective shifts attention from proximate risk factors affecting the health of individuals to an understanding of the health at the level of the population as it is influenced by the social, economic and physical environments (Frank \& Mustard, 1994). This conceptual link recognizes that mental health care requires the adequate provision of social supports.

In 1993, the left-leaning New Democratic Party (NDP) government released Putting People First, a 10year plan for mental health reform. The report appeared in a period of fiscal crisis in the province, and is replete with references to the need to achieve reform within the constraints of existing government budgets (Ontario Ministry of Health, 1994, p. 2). Not surprisingly, while the 1988 document identified eleven key supports, only four (case management; crisis intervention; housing; consumer/survivor and family based supports) are listed in the 1993 document.

Notwithstanding the narrower focus of Putting People First, the report contains explicit recognition that poverty confronts many people with severe mental illness, stating that: "most [people with severe mental illness] are poor, and they have difficulty getting the basics in life, such as shelter and jobs, as well as treatment and community support services' (Ontario Ministry of Health, 1993, p. 15). In a companion report, income support is listed as an essential function of the mental health system alongside emergency care, treatment, and case management (Ontario Ministry of Health, 1994). Insights from population health are again used to draw attention to the role of the social context (1993, p. 3).

In 1995, a neo-conservative 'Progressive Conservative' party won a landslide victory in Ontario, promising sweeping economic and social reforms in the province (Peck, 2001). In 1998, the ministry of health released Making It Happen, outlining key components of a reformed mental health system (Ontario Ministry of Health, 1998). Income supports and sources are identified as elements of a comprehensive continuum of services and supports (1998, p. 14). Elsewhere, the operational framework details three service functions to which people with serious mental illness should have access: "treatment for primary symptoms, rehabilitation to cope with primary symptoms in daily living, and support to sustain a good $Q O L$ and access to social and health care services' (1998, p. 9 emphasis added).

\section{Trends in social assistance}

Recent years have seen substantial change in the funding and provision of social assistance in Canada. At the federal level, limits imposed on transfer payments to provinces through the Canada Assistance Plan (CAP) in the early 1990s, and the replacement of the CAP with the Canada Health and Social Transfer (CHST) in 1995 had far-reaching implications for social spending (Evans, 2002; Peck, 2001). In Ontario, reductions in federal transfer dollars coupled with economic recession and growing debt in the early 1990s led the NDP government to attempt to control social spending. Table 1 shows the value of social assistance received by a single person living with a disability in Ontario for 1989-2001 in constant dollars. Income supports increased in real value from 1989 to 1992, peaked in 1993-1994 and declined slightly in 1995. This about-turn coincides with the period of financial crisis in the province.

Beginning in 1995, the Progressive Conservative government restructured the provincial welfare system drawing heavily on neoliberal rhetoric for its justification (Peck, 2001, p. 236). The government argued that it was essential to control welfare spending and to break the 'cycle of dependency' fostered by existing programs (Ministry of Community and Social Services, 2000). For disabled people, the government replaced existing programs with the 'Ontario Disability Support Program' (ODSP). Under ODSP, social assistance payments for disabled people were frozen so that by 2001 income supports for single disabled persons were worth $11.5 \%$ less than what they had been in 1991 (Table 1). ${ }^{3}$

Largely invisible in the discourse of restructuring have been people with serious mental illness who receive social assistance and reside in residential care facilities or domiciliary hostels. For these people, the majority of social assistance income is paid directly to a third partyfacility/hostel operators - for room and board. As tenants, individuals receive a portion of the ODSP income as a Personal Needs Allowance (PNA) to cover additional monthly expenses. The PNA is currently set at $\$ 112.00$ per month and has not been increased since 1992, meaning its real value fell by $16.5 \%$ between 1992 and $2002 .{ }^{4}$

\footnotetext{
${ }^{3}$ The decline in real value is based on National Council of Welfare figures. The actual value of social assistance for a single disabled person remained constant at $\$ 930.00$ per month for 1995-2002. As a percentage of the poverty line, social assistance for single disabled persons fell from $76 \%$ in $1992-1994$ to $62 \%$ in 2001 .

${ }^{4}$ This figure is based on calculations using Statistics Canada's Consumer Price Index (CPI). The CPI for March 2002 was 119.5 where the 1992 CPI value is set at 100 .
} 
Table 1

Annual social assistance benefits in Ontario for single person with a disability in constant (2001) dollars

\begin{tabular}{ll}
\hline 1989 & $\$ 11,880$ \\
1990 & $\$ 12,677$ \\
1991 & $\$ 12,954$ \\
1992 & $\$ 13,167$ \\
1993 & $\$ 13,087$ \\
1994 & $\$ 13,094$ \\
1995 & $\$ 12,819$ \\
1996 & $\$ 12,613$ \\
1997 & $\$ 12,418$ \\
1998 & $\$ 12,303$ \\
1999 & $\$ 12,085$ \\
2000 & $\$ 11,764$ \\
2001 & $\$ 11,466$ \\
\hline
\end{tabular}

Source: National Council of Welfare (2002).

In restructuring social assistance for disabled persons, the government emphasized the role of informal supports. Thus, ODSP is designed to: 'recognize that government, communities, families and individuals share responsibility for providing [income and employment] supports' (Ministry of Community and Social Services, 1998). In program terms, ODSP permits individuals to receive up to $\$ 4,000$ in gifts annually to supplement their income without penalty, as well as more flexibility for people to keep money from trust funds and inheritances, and an increase in the ceiling for liquid assets. These changes may be seen as an attempt to improve the financial status of people living with disabilities who receive social assistance. Indeed, groups such as the Mental Health Rights Coalition (1997) saw these changes as some of the more agreeable elements of the new program. Yet the decline in the real value of social assistance over the past decade suggests that the government intends material support in the form of gifts and personal assets to substitute for, rather than supplement, formal income support.

\section{Summary}

Income supports continue to be recognized, on paper at least, as a vital part of an effective mental health system. Furthermore, emphasis on income is consistently linked to a conceptualization of mental health as a product of individual functioning and social environment. Despite this recognition, welfare restructuring in Ontario means that the real value of social assistance for people with serious mental illness is less now than at the time when the first of these policy documents was issued. Moreover, residential care facilities tenants have seen an even larger drop in the real value of their income. This decline has been accompanied by greater emphasis on the responsibility of individuals and their supporters to provide the necessary material support. The remainder of the paper examines the implications of these trends for the QOL of people with serious mental illness using a case study of residential care facility tenants in Hamilton, Ontario.

\section{Method \\ Case study research}

Case studies allow researchers to explore the interplay of multiple factors in a given context (Orum, Feagin, \& Sjoberg, 1991). While it can be difficult to generalize from case studies, those grounded in theory (Burawoy, 1991) and representative of other cases (Walton, 1992) can offer broader insight. In this paper, the case study is explicitly connected to QOL scholarship. In addition, the study is grounded in an analysis of the broader transformation of the welfare state in Ontario. Experiences of facility tenants in Hamilton, while shaped by context-specific factors, also share much in common with tenants of facilities and boarding homes in other Canadian cities and other countries (Capponi, 1992; Boydell et al., 1999).

\section{Setting}

The setting for this study is Hamilton, Ontario, a city of approximately 500,000. In Hamilton, Residential Care Facilities (RCFs) provide accommodation for more than 700 people with serious mental illness (Hamilton District Health Council, 2001). ${ }^{5}$ Facilities are privately owned and have been an important source of accommodation since the 1970s. Operators are paid by municipal and provincial governments to provide food, shelter and basic care/rehabilitation.

The research was conducted in collaboration with the Coalition of Residential Care Facility Tenants in Hamilton, a group of current and former tenants. Facility tenants and former tenants formed the coalition in 1996 to advocate for the rights of tenants and the improvement of facility standards. In 1999, the coalition conducted an informal survey of tenants to identify issues of concern. Income emerged as a primary problem. As a supporter of the coalition and university researcher, the author was asked to conduct an exploratory study on income and basic needs among tenants.

\footnotetext{
${ }^{5}$ Until recently, these facilities were known as 'second level lodging homes'.
} 


\section{Interview procedure}

Initial contact with potential participants was made in one of two ways. First, members of the tenants' group were encouraged to identify tenants who might be interested in participating. Second, a housing advocate who is a facilitator for the tenants' group was able to identify potential participants. Subsequently, snowball sampling was used to identify other potential participants. This approach to identifying participants means that the sample population cannot be said to be representative of the larger facility tenant population. One issue of note is the fact that participants were likely more asymptomatic and higher functioning than the larger tenant population. As a result, they may be more likely to have encountered the constraints of poverty in their efforts to participate in leisure activities and social relationships (see Corrigan \& Buican, 1995). Individuals who expressed interest in participating then met with the author, who conducted all interviews and the focus group. All but one of the potential participants had no contact with the author prior to being approached for the study. In accordance with university ethical guidelines, the author explained (orally and in writing) that participation was voluntary, and that the research process was confidential. All of the people approached agreed to participate. Although the location for interviews was flexible, most were conducted at participants' residences. In two instances, interviews were conducted at coffee shops. With the permission of participants, interviews were tape-recorded. The focus group was conducted after the one-on-one interviews had occurred. The author had not planned initially to conduct a focus group, but when seven tenants from a home expressed interest in participating the opportunity presented itself. The focus group took place in the facility dining room and provided an opportunity to validate findings from one-on-one interviews (Hoggart, Lees, \& Davies, 2002).

\section{Participants}

Twenty-two people participated in the study. ${ }^{6}$ All participants had been diagnosed as having a serious mental illness, most commonly schizophrenia. Fourteen participants were male and eight female, while twenty were white, one black and one aboriginal. They ranged in age from 23 to 57, with an average age of approximately 38 years. All participants were single, separated or divorced. Several had adult children. All

\footnotetext{
${ }^{6}$ The number of participants was based partly on data saturation in the sense that over the course of the fifteen oneon-one interviews and the focus group, strong similarities emerged in the issues and experiences mentioned by participants. However, the number was also determined in part by funding constraints for the study.
}

received the PNA. Twelve participants were born in Hamilton, and had spent much of their lives here. Several others had grown up elsewhere in Southern Ontario while two came from outside the province. Length of time in current residence ranged from a few months to more than 11 years, and there was considerable variation in people's living situation prior to their current residence. Some people had been in another facility, and had left either voluntarily or involuntarily. One person had lived at home, while another had lived in an apartment. Two people had been incarcerated, two others had been on the streets, and one had been hospitalized. Most participants had lived in at least two facilities and some as many as ten. Almost all share bedrooms with other people.

\section{Data collection}

Interest in the complex links between poverty and dimensions of QOL made a qualitative approach apposite for this study. Qualitative methods facilitate the elucidation of subjective meanings attached to social circumstances (Patton, 1990). Semi-structured interviews using open-ended questions allow for responses that are unexpected, and may describe people's views and feelings more closely than fixed response categories (Fowler, 1993). Second, through in-depth consideration of individuals' experiences, qualitative methods allow for an examination of ways in which multiple factors intersect in and shape particular social contexts (Hoggart et al., 2002). Finally, qualitative methods shed light on the agency of even the most marginalized people as they respond to opportunities and challenges in daily life (Boydell et al., 1999).

The interview guide for the study was produced through a collaborative process involving the tenants' committee. At two committee meetings with the author present, members discussed issues of importance connected to income and poverty while the author took notes. The input of coalition members was a valuable characteristic of the study, particularly as there has been little effort to identify mental health consumers' research priorities (Cohen, 2000b). In discussions, members focused on the link between income and basic needs, but also cited issues such as constraints on daily activities and boredom. Their emphasis mirrors research that identified basic needs as a significant predictor of QOL among people with serious mental illness (UK700 Group, 1999). Alongside the committee's input, the author drew on the literature to formulate questions on other QOL domains. Ultimately, the interview guide included items to elicit factual information and subjective opinions on: income, basic needs, living situation, social relationships, family, leisure activities, self-esteem and demographic information. 


\section{Analysis}

Tapes from the interviews and focus group were transcribed in full. Interviews were initially read repeatedly, and were then entered into the qualitative analysis software, NUD-IST. In the analysis, the broad themes developed for the interview guide were used as the major categories for the organization of data. More detailed coding and analysis within each of these categories was then pursued with a primary focus on the implications of poverty in the daily lives of participants. This approach to analysis is akin to the 'selective coding' approach outlined by Strauss and Corbin (1990), in which a combination of inductive and deductive thinking is used to identify conceptual patterns and relationships in the data. The approach allowed for some unexpected themes to emerge from the study. For example, in the course of analysis participants' concerns about their inability to purchase Christmas gifts emerged as an important issue in connection with family relationships and reciprocity. In the next section, results of the analysis are presented. Sources of income and participants' ability to meet basic needs are discussed first. Subsequently, attention is focused on poverty's impact on family, social relationships, daily activities, and self-esteem as 'life domains' that contribute to QOL.

\section{Results}

\section{Meeting basic needs}

Participants were asked initially to identify all sources of income. All reported that the PNA was their primary source of income, while seventeen said it was currently their only source of income. People also listed annual tax credits as vital sources of income, as well as Canadian Mental Health Association clothing vouchers redeemable at goodwill stores. Five men had some casual or part-time employment. Research indicates that paid work provides opportunity for meaningful activity, and carries positive implications for self-esteem and social identity (Kelly et al., 2001), but it also has material significance. For example, Daren is in his early fifties and has a diagnosis of schizophrenia. He spent considerable time on the streets and in local shelters before moving into a lodging home about a year before the interview. ${ }^{7}$ Daren's PNA income is paid to the facility operator who deducts money for cigarettes and other expenses leaving him only eight dollars a week. He works shoveling neighbor's snow in the winter and does occasional manual labor for his uncle. While he

\footnotetext{
${ }^{7}$ Participants' names have been changed to ensure confidentiality.
}

enjoys being active, the work also provides vital extra income.

Among participants who were not working, some felt they would be unable to hold down a regular job because of mental illness and/or medication. Others expressed interest in working but were concerned, and sometimes confused, about rules governing employment earnings while on social assistance (also Turton, 2001). ${ }^{8}$ None of the women participants had paid employment, a finding consistent with Lehman, Rachuba, and Postrado (1995) who suggest that male board-and-care residents tended to be better off materially than women in part because of differential access to temporary and casual work.

Twelve participants said they occasionally received financial assistance and/or gifts from families or that they could borrow money from family members if necessary, but most indicated they did not like to ask. Five people were not in touch with family while five others indicated that they try not to ask family for money. These responses are significant in light of the changes introduced under the ODSP program to allow for additional family support and personal assets for people on social assistance. For a significant number of participants in this study, the ability to receive more support from family members makes little difference because families are unable to help, individuals are reluctant to ask, or people are no longer in contact with family members.

Asked about monthly expenses, participants indicated that most of their income was spent on basic needs such as clothes, shoes, toiletry supplies, haircuts, as well as cigarettes, food, newspapers, transportation, and leisure (going for coffee/tea, cinema, video rental, etc). Twentyone participants said they were unable to meet basic monthly needs. Asked to identify specific items they could not afford, people most often identified more clothing and toiletry supplies, better shoes, as well as books, magazines, bedding and items such as winter coats or CD players.

For example, Laura is forty-three and has a diagnosis of paranoid schizophrenia. She has lived in her current facility for 3 years and the PNA is her only income. She receives no material support from family members. Most of Laura's monthly income is spent on toiletries, food, clothing and shoes, and occasional trips to a nearby coffee shop. She buys clothes at thrift stores or discount retailers, and tries to save money to buy shoes that will last longer. Laura said she would like more clothes and cosmetics. She feels frustrated about not being able to afford these items, but:

\footnotetext{
${ }^{8}$ ODSP regulations allow people to make $\$ 160$ per month without incurring penalties. One participant thought, incorrectly, that he would have to work full time to earn this amount.
} 
I guess you just have to accept it and go on. You budget out your money at the beginning of the month and figure out how much you can spend every day, and when I see something that I'd like, well, you know that you just can't have it. I buy cheaper things with the clothing. I limit myself to a couple of coffees per week. I don't go to [the cinema] or anything like that and I watch a lot of television (Laura)

Despite efforts to budget, Laura frequently runs out of money two or three weeks into the month. Other participants identified similar problems. The following statement from Louise is significant for the connection made between poverty and satisfaction with immediate living conditions, a factor in overall QOL. Asked about unmet needs, she replied:

Clothes and umm (.) and different things for my room like maybe a bedspread, some new sheets and things for the walls to brighten (.) because our room is very dull. we don't have much light in there. ${ }^{9}$

Several participants cited food as an immediate need, expressing concern about the quantity and quality of facility meals, as well as the high cost of supplementing these meals with other food items. Their concerns are supported by research that found over half of the city's lodging homes were providing tenants with meals that had little nutritional value (Davy, 1992).

Meeting basic needs is particularly difficult for people who smoke. Cigarettes consume between one third and one half of some participants' income. The incidence of smoking among people with serious mental illness is significantly higher than the general population, but it is not clear why this is the case (Leonard et al., 2001). Smoking may function as a form of self-medication, particularly for people with schizophrenia (Lawn, Pols, \& Barber, 2002). At the same time, smoking is a stigmatized activity, doubly so for people on social assistance, and several participants expressed concern that others would view their financial predicament less favorably because they smoked.

Asked how they made do with limited resources, participants identified a range of short-term strategies. Strategies most often mentioned included careful budgeting (14 persons), shopping only at thrift store and discount outlets (11), bargain hunting (8), borrowing money (typically from facility managers) (7), doing without (5), and putting money aside for essential items (5). Less frequently used strategies included selling the monthly bus pass tenants receive from the municipality (3), pawning personal items (2), panhandling (2) and shoplifting (1). Despite using these strategies, most participants (20) said their income was typically

\footnotetext{
${ }^{9} \mathrm{~A}$ dot in parentheses is used to indicate a slight pause in participants' statements.
}

exhausted before the end of the month. ${ }^{10}$ Moreover, some strategies come at a cost. Borrowing money traps people in a cycle of debt while selling the bus pass greatly restricts geographic mobility. In addition to these short-term strategies, participants (12) talked about saving money as a way to improve their financial security, but only two people had savings at the time of the interview.

\section{Family relations}

Positive relationships with family members constitute an important influence on mental health and well-being for the population as a whole (Kawachi \& Berkman, 2001). Moreover, studies indicate that supportive interactions with family members contribute to overall QOL for people with mental illness more specifically (Corrigan \& Buican, 1995; Hannum et al., 1994; Nelson, Wiltshire, Hall, Peirson, \& Walsh-Bowers, 1995). In the general population, support from friends and family is correlated with income (Advisory Committee on Population Health, 1999). For people with serious mental illness, the current study suggests that poverty impacts on people's ability to develop and sustain relationships with family members in several ways.

Contact with family members is hindered directly by material shortage. Opportunities to communicate with or visit family members were constrained by lack of income. Two people spoke about the cost of longdistance phone cards needed to speak with parents and family members who did not live nearby. Other people talked about the costs of public transportation. Louise is in her early fifties and has a diagnosis of schizophrenia. She had lived at her current residence for 5 years, and had lived in the city for more than two decades, first by herself and then in a number of residential facilities. Louise is originally from a neighboring town, where her mother still resides. In the interview she talked about the importance of visiting her mother.

I try to go to visit my mother once a month and she can't always pick me up because the car is giving her problems, and she's getting older and she won't be able to drive. You know, she's seventy-five now and she won't be driving for much longer. [Author: how do you get there?] By bus, it's three-oh-five [\$3.05] but one way or another I try and get there. I put money aside and try to see her because she lives alone. My father died.

This statement is significant for the link between Louise's limited income and her capacity to visit an aging parent, but it is also important to recognize the reciprocal nature of the relationship (Nelson et al.,

\footnotetext{
${ }^{10}$ Most participants indicated that their income lasted between two and three weeks.
} 
1995). The monthly trips allow Louise to perform the role of caregiver, something that may be important for her self-esteem.

The theme of reciprocity also appeared in connection with the holiday season. Given the timing of the interviews (early to mid-January), the holiday season was identified by many people in connection with their families, and elicited considerable discussion in the focus group. Some participants spoke about their inability to afford gifts. Gerald lamented:

I can't even buy my grandchildren things for Christmas or anything like that. You just send them a lousy card. You feel torn apart.

Others noted the costs incurred in their efforts to purchase gifts for family members. Pete, a participant in the focus group in his mid-thirties, had pawned his guitar so that he could buy gifts for his parents. For participants, gift giving may contribute to a sense that they are active members of a family network, rather than passive recipients of others' good will. In conceptual terms, these sentiments raise questions about the material dimension of social network transactions. In existing work, networks facilitate four kinds of supportive transactions: emotional, social, tangible and problem solving (Nelson, Hall, Squire, \& Walsh-Bowers, 1992), but it is not clear how material relations intersect with these transactions.

Participants' experiences may shed further light on this issue. Alongside the direct constraints of material shortage, poverty led at least six participants to avoid interactions with family members. In her early thirties, Maggie has a diagnosis of borderline personality disorder. Originally from a small town some distance from Hamilton, Maggie had moved to the city and into her current residence eight months before the interview, following hospitalization. Although most of her family is not local, Maggie has two sisters in the city. Asked about contact with her siblings, Maggie expressed frustration:

I like to go for coffees with my friends, but I don't have the money for it. You know, I can't even go visit my sisters because I can't go out with them. I can't ask them to pay for my coffees or whatever because I don't want to feel like a bum all the time (Maggie)

Experiences like this raise concerns about the provision of informal support. Studies consistently emphasize the importance of family support for the QOL of people with serious mental illness. The same emphasis is found in the policy documents reviewed above. ${ }^{11}$ At the same

\footnotetext{
${ }^{11}$ Building Community Support and Putting People First identify informal supports as essential to the mental health care system. The language of Making It Happen reflects a shift away from a community-empowerment model (Nelson et al., 2001), but families are identified as 'active and valued participants' in mental health care.
}

time, people with serious mental illness tend to have smaller than average social networks, and rely more heavily on family members for support (Caron, Tempier, Mercier, \& Leouffre, 1998; Hannum et al., 1994). While the smaller networks may be partly a product of reduced interpersonal functioning (Lehman et al., 1995), participants' experiences indicate that poverty also works against an ability to sustain close ties with family, limiting communication and affecting people's willingness to engage in social activities.

Changes introduced under ODSP may further strain family ties. Greater flexibility for material support from family is identified as a key innovation of the new program. However, many participants feel that they should not depend, or already rely too heavily, on their families. These concerns lead some people to decline opportunities for contact with parents, siblings and children. Continued emphasis on the role of family to provide material support in lieu of an adjustment in the PNA may act as an added stressor, further limiting people's willingness and/or ability to draw on informal support. In turn, this may impact people's overall QOL.

\section{Friendships and intimate relations}

Alongside family, friends and confidants are also important in the daily lives of people with serious mental illness (Hannum et al., 1994). Both the number of relationships people have, and their subjective satisfaction with those relationships have significance for QOL (Corrigan \& Buican, 1995; Trauer et al., 1998). Participants in this study most often identified other tenants as friends, a finding consistent with Aubry and Myner (1996). These are the people with whom they spend the most time, and with whom they share cigarettes and food. For some, the importance of these friendships is paramount. In his mid-thirties, Mark had lived in his facility for several years. He commented:

Everybody in here (.) it's like the longer you stay here, the people here just kind of become your family. It's hard to explain. Everybody tries to get along...

This sense of connection was not true for everyone, and depended in part on the makeup of the facility population as well as length of residency. In an extreme case, Keith had left his last facility after harassment from another tenant. Mike had only recently arrived at his house and did not consider any of the fellow tenants as friends. Participants sometimes contrast the strength of facility friendships with problems developing or sustaining them outside. In some instances, income was cited as a factor. For example, Rob is in his early forties and has a diagnosis of manic depression. He had 
lived in his current residence for about eight months and before that had been living at a shelter. He identified the four men with whom he shared a floor of the facility as friends. Asked about friends outside the facility, he said:

People get tired of always having to dig in for you as well 'cause like things are tough for everybody, for a lot of people and you don't want to have to be paying for someone else's way all the time.

In addition to friendships, three men said that they currently had girlfriends, while six others indicated they would like to meet girlfriends. ${ }^{12}$ Both groups commented on the challenge that developing and/or sustaining these relationships posed in financial terms. For example:

I haven't gone to a movie in so long. I can't remember when. My girlfriend works, but she doesn't make a heck of a lot of money so I don't want to lean on her. I don't want to keep bringing up the problem of the [mumbles] (Luke)

It really cuts in to your social life. Like if I meet a girl or something, I couldn't afford to take her to dinner, or even if we went Dutch treat I'd have a hard time budgeting. The best I could do is take her out for a coffee, but if things progressed along... (Rob)

Income is not the only factor constraining participants in their efforts to develop and sustain friendships and intimate relationships. Reduced interpersonal functioning as a product of mental illness may play a role, and several participants said they felt embarrassed telling potential friends or girlfriends that they lived in facilities. However, poverty clearly does limit social contact with people outside the facility and opportunities to foster intimate relationships. Moreover, people's ability to develop friendships and intimate relationships depends in part upon opportunities for leisure activities outside the house. This point is addressed in the next section.

\section{Leisure activities}

Leisure activity and community participation more broadly are domains that make significant contributions to overall QOL for people with serious mental illness (Kelly et al., 2001; Nelson et al., 1995; Trauer et al., 1998). In the current study, participants were asked about their weekly activities in and outside the house with particular emphasis on leisure. Activities most commonly listed included going to a coffee shop, going for a walk, the movies, going to the mall/shopping,

\footnotetext{
${ }^{12}$ None of the women participants talked about finding partners, but this may have been in part because the interviewer was male.
}

watching television, going to the park, the YMCA (gym), eating at a fast food restaurant, and riding the bus. There was some variation in frequency of activities among participants. At one extreme, three people said they spent much of their time inside watching television, while two others reported leaving their facilities two or three times a day to pass the time. ${ }^{13}$ Notwithstanding these variations, participants talked about the importance of leisure activities, particularly those that enabled them to leave the facility. At the same time, all but one of the participants expressed dissatisfaction with their leisure activities. The following statements are representative of their concerns, and illustrate the immediate impact of poverty.

What I'd like to do is to go out to supper, not expensive places, but just to go out for a hamburger or something like that, just once a month or once every two months even (.) I don't go now because I can't afford it. (Louise)

Once you buy your clothes and your personal stuff, it really doesn't leave you that much money because if you want to go to a movie or something, you know, treat yourself to something, sometimes you can't. [Author: how do you feel about that?] Sometimes it makes you, you know, angry (Geoff)

In addition to the direct impact of poverty, income constrained activities in other ways. A lack of appropriate clothing made it difficult to engage in leisure activities. This was true in a functional sense (having a decent winter coat or gym shoes) and aesthetically (not feeling comfortable in what one is wearing), a point addressed in more detail below. Participants also said that a lack of income sometimes made them feel 'out of place.' Going for a coffee was the 'leisure' activity most commonly identified by participants. A visit to a coffee shop means time away from the facility and, in winter months, somewhere warm to hang out, but tenants' desire to spend time in these establishments can conflict with management policy. Coffee shops may limit clients to twenty minutes' occupancy while restaurants may require customers to purchase food. In some instances, this led to problems for participants. Keith, in his early forties has a diagnosis of schizophrenia. He described an incident at a local restaurant:

I like to go to [name] restaurant for a coffee or something. I was barred there for using too many of the creamers... They like you to buy a meal, but you can't do what other people do. You want to, even at a lower level. (Keith)

\footnotetext{
${ }^{13}$ Interviews were conducted in January with temperatures below freezing so many participants had curtailed trips outside the house.
} 
Again, income is not the only factor shaping leisure activities. Ability to participate in activities outside the house is also shaped by the municipal policy that provides monthly bus passes at no cost to residential care facility tenants. However, the city is currently facing a budget crisis and is proposing to discontinue the bus pass. If approved, the cut will have a substantial impact on tenants' budgets and their ability to engage in activities outside the house.

\section{Self-esteem and social stigma}

Effort was also made to examine the extent to which financial difficulties affect participants' self-esteem and their experience of social stigma. Studies consistently identify individual self-esteem/well-being as a key domain of QOL (Atkinson \& Zibin, 1996; Lehman, 1999). Drawing on population health research, provincial policy documents consistently recognize that the extent to which people have appropriate housing, adequate income/employment and other social factors has an important influence on health and well-being. Ongoing work in population health documents the impact of relative deprivation on health. In addition to the impact of absolute deprivation (material scarcity), standard of living relative to other people affects health at both individual and collective levels (Kawachi, Kennedy, \& Wilkinson, 1999). While research on relative deprivation has focused on the population at large, the implications may have relevance for people with serious mental illness as a disproportionately poor and stigmatized population.

In the current study, participants gave many examples of situations in which relative deprivation contributed to diminished self-esteem and a stigmatized self-image. One of the clearest themes to emerge in analysis involved clothing. Almost all participants were concerned about old, poorly fitting or cheap clothing, but younger participants may be acutely aware of an inability to 'fit in' (Segal \& Vandervoort, 1996). For example, Mike is in his mid-twenties and has a diagnosis of schizophrenia. He had moved into his facility a few months before, after a short stay at a psychiatric hospital. Prior to that, he had been living at a homeless shelter. In the interview, he spoke repeatedly about his lack of clothing. Asked if he often went out, he replied:

NO, you got nothing to go out with. Look, if you want to buy a jacket or something like that, a decent jacket could be fifty or a hundred, and it's wintertime. In the summer you might be able to just go in a shirt but (.) that's basically it, but I mean you've got to get clothes that match the pants right, and the Salvation Army is kind of a joke. It's old man's clothes. YOU LOOK STUPID!
Clothing is important to one's presentation of self to others and one's self-esteem (Turner-Bowker, 2001). Studies also suggest that people present themselves more confidently if they feel well dressed (Schneider, 1974), something that may hold implications for participants' interactions in the community.

A closely related issue concerns the link between poverty and social stigma. Stigma is a major barrier to participation and inclusion for people with serious mental illness (Wahl, 1999). While stigma derives in part from enduring stereotypes about the 'strangeness' of mental illness (Dear, Gaber, Takahashi, \& Wilton, 1997), it may also be reproduced by the intersection of mental illness and poverty where the latter contributes to the 'visibly different' status of people with serious mental illness. For example, chronic poverty makes it difficult to manage personal appearance. Many participants cannot afford decent clothes, hygiene products and regular haircuts. As a result:

You don't fit in. You've got to go [out] dressed like this, and that's what you got. You're conscious of what you look like. You automatically look like a bum. If I didn't have the [wheelchair]... I'd automatically just blend in as a bum. (Gerald)

In research on public reactions to a community mental health facility, Reda (1996) reported that three quarters of participants believed that 'mentally ill people' could be identified by traits such as bizarre behavior, poor social skills and behavior disturbing to the public. Perceptions of bizarre behavior or poor social skills may at the very least be exaggerated by poverty if a lack of resources forces people to wear old or unmatched clothing and do without personal care items.

More generally, when asked how they felt about their financial situation, participants' responses show how chronic poverty and relative deprivation contribute to an erosion of self-esteem. For example:

It makes me feel kind of down because you can't go places. (Laura)

It's more than someone on the street is getting, but it's not enough to live on. It gives me a headache sometimes. It can stress you out sometimes, just money (Nick)

You have to depend on other people, and who wants to depend on other people all the time. Sure, it's nice but it's like begging. It's the same thing (Gerald)

Together, participants' experiences suggest that while population health has figured consistently in recent policy documents concerning mental health reform, the lessons of a population health perspective, particularly 
as they relate to income support, have yet to find expression in practice.

\section{Conclusion}

This paper examined the effects of poverty on people with serious mental illness in a context of mental health reform and welfare restructuring. An analysis of recent trends in mental health care and social assistance policy in Ontario revealed that while income support has been recognized as a core element of mental health care, welfare restructuring has led to a significant decline in the real value of income supports over the last decade. Qualitative data obtained from twenty-two residential care facility tenants in Hamilton, Ontario was then analyzed to provide insight into the implications of this trend for the QOL of people with serious mental illness. Participants in the study relied on social assistance as their primary or sole source of income. All experienced chronic poverty and most were unable to meet basic monthly needs. Poverty was also shown to have a deleterious impact on other areas of tenants' lives. Lack of income worked against contact with family members and constrained individuals in their efforts to build social and intimate relations. In addition, poverty contributed to a diminution of selfesteem and an exacerbation of social stigma among participants.

By necessity, this is a small exploratory study, and the participants are not necessarily representative of the larger residential care facility tenant population. The fact that tenants are likely higher functioning that the facility population as a whole suggests that they may be more likely, for example, to have faced the constraints of poverty in their social relations and leisure activities. Notwithstanding these limitations, a number of broader implications emerge out of the insights provided by participants. In policy terms, the study affirms the need to recognize material resources as a central element of mental health policy. Consumers find ways to deal with poverty, but they also articulate how additional income would improve their QOL. The review of recent mental health policy documents in Ontario raises troubling questions since key policy statements released by three different governments consistently cite adequate income as an essential part of a reformed mental health system. However, government decisions to freeze social assistance means that the real value of the monthly income received by residential care facility tenants in the province has fallen by more than $16 \%$ in the last decade.

The disjuncture between mental health policy and welfare restructuring has negative implications for people who rely on the PNA. As participants in this study demonstrated, multiple 'life domains' that contribute to overall QOL are negatively affected by poverty. For example, mental health scholarship and government policy affirm the importance of informal social supports in consumers' lives, but a combination of chronic poverty and additional demands for financial assistance threaten these informal supports and, by extension, the quality of people's lives in the community.

In Hamilton, the Coalition of Residential Care Facility Tenants attempted to calculate a dollar value for a livable allowance. Members assembled a list of basic needs including goods (clothing, coats, shoes, hygiene products, etc) and services (haircuts) and priced these items to establish a monthly average. Cognizant of the politics of welfare, neither cigarettes nor leisure activities were included in the calculations. The monthly figure came to approximately $\$ 160 .{ }^{14}$ The group and other organizations, such as Ontario's Psychiatric Patients Advocacy Office, have since used this figure as the basis for appeals to the provincial government to address the inadequacy of the PNA. While social activities were not included in the calculations, an increase of this amount would likely provide a small discretionary income that could make an important difference in everyday life. The issue is not about conformity and consumption, but about findings ways to foster inclusion and to reduce the stigma of mental illness.

In this sense, the goal of increasing tenants' income is consistent with the larger aims of community mental health care and consumer empowerment (Rappaport, 1987). ${ }^{15}$ It is also consistent with research identifying a 'minimum income for healthy living' that provides decent food, shelter and clothing plus opportunities for activities that foster social integration (Morris, Donkin, Wonderling, Wilkinson, \& Dowler, 2000). Last but by no means least, the goal of increasing the PNA is consistent with the recognition that poverty restricts disabled people's rights to social and political participation (Beresford, 1996). However, this goal will not be easy to accomplish. While the ministry of health identifies income support as essential to a reformed mental health system, a primary aim of the government in recent years has been to curb welfare spending in the name of taxpayer accountability and personal responsibility. Ultimately, a continuing failure to address the material circumstances of people with serious mental illness will limit the effectiveness of the mental health care system as a whole and work against improvements in individuals' QOL.

\footnotetext{
${ }^{14}$ The figure for women was slightly higher, reflecting the additional cost of personal care items.

${ }^{15}$ Efforts might also usefully focus on increasing the earned income limit for people receiving ODSP benefits, and by educating people about the rules governing paid work.
} 


\section{Acknowledgements}

My thanks to Robert Earickson, Cynthia Cranford and two anonymous reviewers for helpful comments and suggestions on an earlier draft of this paper.

\section{References}

Advisory Committee on Population Health. (1999). Statistical Report on the Health of Canadians. Ottawa: Health Canada.

Atkinson, M., \& Zibin, S. (1996). Quality of life measurement among persons with chronic mental illness: A critique of measures and methods. Ottawa: Health Canada.

Aubry, T., \& Myner, J. (1996). Community integration and quality of life. Canadian Journal of Community Mental Health, 15, 5-20.

Batavia, A., \& Beaulaurier, R. (2001). The financial vulnerability of people with disabilities: Assessing poverty risks. Journal of Sociology and Social Welfare, 28, 139-162.

Beresford, P. (1996). Poverty and disabled people: Challenging dominant debates and policies. Disability and Society, 11, 553-567.

Bigelow, D., Gareau, M., \& Young, D. (1990). A quality of life interview. Psychosocial Rehabilitation Journal, 14, 94-98.

Boydell, K., Gladstone, B., Crawford, E., \& Trainor, J. (1999). Making do on the outside: Everyday life in the neighbourhoods of people with psychiatric disabilities. Psychiatric Rehabilitation Journal, 23, 11-18.

Burawoy, M. (1991). The extended case method. In M. Burawoy (Ed.), Ethnography Unbound: Power and resistance in the modern metropolis (pp. 271-287). Berkeley: University of California Press.

Capponi, P. (1992). Upstairs at the crazy house: The life of a psychiatric survivor. Toronto: Viking.

Capponi, P. (1997). Dispatches from the poverty line. Toronto: Penguin.

Carling, P., \& Curtis, L. (1997). Implementing supported housing: Current trends and future directions. New Directions for Mental Health Services, 74, 79-94.

Carne, B. (1998). A consumer perspective. Canadian Journal of Community Mental Health, 3(Suppl.), 21-28.

Caron, J., Tempier, R., Mercier, C., \& Leouffre, P. (1998). Components of social support and quality of life in severely mentally ill, low-income individuals and a general population group. Community Mental Health Journal, 34, 459-475.

Chappell, R. (2000). Social welfare in Canadian society. Toronto: ITP Nelson.

Cohen, C. (1993). Poverty and the course of schizophrenia: Implications for research and policy. Hospital and Community Psychiatry, 44, 951-958.

Cohen, C. (2000a). Overcoming social amnesia: The role for a social perspective in psychiatric research and practice. Psychiatric Services, 51, 72-78.

Cohen, C. (2000b). Consumer preferences for psychiatric research. Psychiatric Services, 51, 936.

Corrigan, P., \& Buican, B. (1995). The construct validity of subjective quality of life for the severely mentally ill. Journal of Nervous and Mental Disease, 183, 281-285.
Davy, D. (1992). No nutritional value: study critical of lodging homes' food. Hamilton Spectator, February 12, B2.

Dear, M., Gaber, S., Takahashi, L., \& Wilton, R. (1997). Seeing people differently: Changing constructs of disability and difference. Environment and Planning D, 15, 455-480.

Dear, M., \& Wolch, J. (1987). Landscapes of despair: From deinstitutionalization to homelessness. Princeton, NJ: Princeton University Press.

Dickinson, H. (2001). Mental health policy in Canada: what's the problem? In B. Singh Bolaria, \& H. Dickinson (Eds.), Health, illness, and health care in Canada (pp. 372-388). Toronto: Harcourt Brace.

Draine, J., Salzer, M., Culhane, D., \& Hadley, T. (2002). Role of social disadvantage in crime, joblessness, and homelessness among persons with serious mental illness. Psychiatric Services, 53, 565-575.

Estroff, S., Zimmer, C., Lachiotte, W., Benoit, J., \& Patrick, D. (1996). No other way to go: Pathways to disability income application among persons with severe and persistent mental illness. In R. Bonnie, \& J. Monghan (Eds.), Mental disorder, work disability, and the law (pp. 55-104). Chicago: University of Chicago Press.

Evans, P. (2002). Downloading the welfare state, Canadian style. In G. Schaffner-Goldberg, \& M. Rosenthal (Eds.), Diminishing Welfare: A cross-national study of social provision (pp. 75-102). Westport, CT, London: Auburn House.

Everett, B. (2000). A fragile revolution: Consumers and psychiatric survivors confront the power of the mental health system. Waterloo, ON: Wilfrid Laurier University Press.

Fawcett, G. (1996). Living with disability in Canada: An economic portrait. Quebec: HRDC Office for Disability Issues.

Fowler, F. (1993). Survey research methods. Thousand Oaks, CA: Sage Publications.

Frank, J., \& Mustard, J. F. (1994). The determinants of health from a historical perspective. Daedalus, 123(4), 1-19.

Goldman, H. (1999). The obligation of mental health services to the least well off. Psychiatric Services, 50, 659-663.

Hamilton District Health Council. (2001). Housing and support requirements for persons with serious mental illness. Hamilton, Ontario: Hamilton District Health Council.

Handler, J., \& Hasenfeld, Y. (1997). We the poor people: Work, poverty and welfare. New Haven and London: Yale University Press.

Hannum, R., Myers-Parrelli, A., Schoenfeld, P., Cameron, C., Campbell, H., \& Chrismer, L. (1994). Promoting social integration among people with psychiatric disabilities. Innovations and Research, 3, 17-23.

Hoggart, K., Lees, L., \& Davies, A. (2002). Researching human geography. London: Arnold.

Huxley, P., \& Warner, R. (1992). Case management, quality of life, and satisfaction with services of long-term psychiatric patients. Hospital and Community Psychiatry, 43, 799-802.

Kawachi, I., \& Berkman, L. (2001). Social ties and mental health. Journal of Urban Health, 78, 458-467.

Kawachi, I., Kennedy, B., \& Wilkinson, R. (Ed.), (1999). The society and population health reader: Income inequality and health. New York: The New Press. 
Kearns, R. (1990). Satisfaction with community life among chronically mentally disabled persons in Auckland. Community Mental Health in New Zealand, 5, 47-63.

Kelly, S., McKenna, H., Parahoo, K., \& DuSoir, A. (2001). The relationship between involvement in activities and quality of life for people with severe and enduring mental illness. Journal of psychiatric and mental health nursing, 8, 139-146.

Lam, J., \& Rosenheck, R. (2000). Correlates of improvement in quality of life among homeless persons with serious mental illness. Psychiatric Services, 51, 116-118.

Langan, M. (1998). Welfare: Needs, rights and risks. New York: Routledge.

Lawn, S., Pols, G., \& Barber, J. (2002). Smoking and quitting: A qualitative study with community-living psychiatric clients. Social Science \& Medicine, 54, 93-104.

Lehman, A. (1983). The well-being of chronic mental patients. Archives of General Psychiatry, 40, 369-373.

Lehman, A. (1999). A review of instruments for measuring quality-of-life outcomes in mental health. In N. Miller, \& K. Magruder (Eds.), Cost-effectiveness of psychotherapy: A guide for practitioners, researchers and policymakers (pp. 174-181). New York: Oxford University Press.

Lehman, A., Rachuba, L., \& Postrado, L. (1995). Demographic influences on quality of life among persons with chronic mental illnesses. Evaluation-and-Program-Planning, 18, 155-164.

Leonard, S., Adler, L., Benhammou, K., Berger, R., Breese, C., Drebing, C., Gault, J., Lee, M., \& Logel, J., et al. (2001). Smoking and mental illness. Pharmacology, Biochemistry and Behavior, 70, 561-570.

Lord, J., \& Dufort, F., (Ed.) (1996). Power and oppression in mental health. Canadian Journal of Community Mental Health 15, 1-185.

Lott, B., \& Bullock, H. (2001). Who are the poor? Journal of Social Issues, 57, 189-206.

Lurigio, A., \& Lewis, D. (1989). Worlds that fail: A longitudinal study of urban mental patients. Journal of Social Issues, 45, 79-90.

Mental Health Rights Coalition of Hamilton-Wentworth. (1997). Submission to the standing committee on social development re: Bill 142 The Social Assistance Reform Act. October 23 (available from the author).

Morris, J., Donkin, A., Wonderling, D., Wilkinson, P., \& Dowler, E. (2000). A minimum income for healthy living. Journal of Epidemiology and Community Health, 54, 885-889.

National Council of Welfare. (2002). Welfare Incomes 2000 and 2001. Ottawa: National Council of Welfare.

Nelson, G., Hall, G. B., Squire, D., \& Walsh-Bowers, R. (1992). Social network transactions of psychiatric patients. Social Science \& Medicine, 34, 433-445.

Nelson, G., Lord, J., \& Ochocka, J. (2001). Shifting the paradigm in community mental health: Towards empowerment and community. Toronto: University of Toronto Press.

Nelson, G., Wiltshire, C., Hall, G. B., Peirson, L., \& WalshBowers, R. (1995). Psychiatric consumer/survivors' quality of life: Quantitative and qualitative perspectives. Journal of Community Psychology, 23, 216-233.

Newman, S. (1994). The housing and neighbourhood conditions of persons with severe mental illness. Hospital and Community Psychiatry, 45, 338-343.
Oliver, J. (1992). The social care directive: Development of a quality of life profile for use in community services for the mentally ill. Social Work and Social Sciences Review, 3, $5-45$.

Ontario Ministry of Community and Social Services. (1998). Press release: Ontario keeps it promise to create new income and employment support program for people with disability (June 1) available from www.gov.on.ca/CSS/page/news/ news 1998 .

Ontario Ministry of Community and Social Services. (2000). Making welfare work: Report to the taxpayers on welfare reform. Toronto: The Ministry.

Ontario Ministry of Health. (1988). Building Community Support for People: A plan for mental health in Ontario. Toronto: The Ministry.

Ontario Ministry of Health. (1993). Putting people first: The reform of mental health services in Ontario. Toronto: The Ministry.

Ontario Ministry of Health. (1994). Implementation planning guidelines for mental health reform. Toronto: The Ministry.

Ontario Ministry of Health. (1998). Making it happen: Implementation plan for mental health reform. Toronto: The Ministry.

Orum, A., Feagin, J., \& Sjoberg, G. (1991). A case for the case study. Chapel Hill, NC: University of North Carolina Press.

Patton, M. (1990). Qualitative methods. Thousand Oaks, CA: Sage Publications.

Peck, J. (2001). Workfare states. New York and London: The Guilford Press.

Rappaport, J. (1987). Terms of empowerment/exemplars of prevention: Toward a theory for community psychology. American Journal of Community Psychology, 15, 122-144.

Reda, S. (1996). Public perception of discharged psychiatric patients: A community survey. International Journal of Social Psychiatry, 42, 220-229.

Rosenheck, R. (1999). Principles for priority setting in mental health services and their implications for the least well off. Psychiatric Services, 50, 653-658.

Russell, M. (1998). Beyond ramps: Disability at the end of the social contract. New York: Vintage Press.

Saraceno, B., \& Barbui, C. (1997). Poverty and mental illness. Canadian Journal of Psychiatry, 42, 285-290.

Schneider, D. (1974). Effects of dress on self-presentation. Psychological Reports, 35, 167-170.

Segal, S., \& Vandervoort, D. (1996). Differences in daily hassle patterns among California's seriously mental ill sheltered care residents. Adult Residential Care Journal, 10, 54-65.

Shore, M. (1997). Psychological factors in poverty. In L. Mead (Ed.), The New Paternalism: Supervisory Approaches to Poverty (pp. 305-329). Washington, DC: Brookings Institute Press.

Strauss, A., \& Corbin, J. (1990). Basics of qualitative research: Grounded theory procedures and techniques. Newbury Park, CA: Sage Publications.

Thoits, P. (1995). Stress, coping and social support processes: Where are we? what next? Journal of Health and Social Behavior, 37(Suppl.), 53-79.

Trauer, T., Duckmanton, R., \& Chiu, E. (1998). A study of the quality of life of the severely mentally ill. International Journal of Social Psychiatry, 44, 71-79. 
Turner-Bowker, D. (2001). How can you pull yourself up by your bootstraps, if you don't have boots? Work-appropriate clothing for poor women. Journal of Social Issues, 57, 311-322.

Turton, N. (2001). Welfare benefits and work disincentives. Journal of Mental Health, 10, 285-300.

UK700 Group. (1999). Predictors of quality of life in people with severe mental illness. British Journal of Psychiatry 175, 426-432.

Wahl, O. (1999). Mental health consumers' experience of stigma. Schizophrenia Bulletin, 25, 467-478.

Walton, J. (1992). Making the theoretical case. In C. Ragin, \& H. Becker (Eds.), What is a case? Exploring the foundations of social inquiry (pp. 121-137). Cambridge, MA: Harvard University Press.

Ware, N., \& Goldfinger, S. (1997). Poverty and rehabilitation in severe psychiatric disorders. Psychiatric Rehabilitation Journal, 21, 3.

Wilson, S. (1996). Consumer empowerment in the mental health field. Canadian Journal of Community Mental Health, $15,69-85$.

Yanos, P., Rosenfield, S., \& Horwitz, A. (2001). Negative and supportive social interactions and quality of life among persons diagnosed with severe mental illness. Community Mental Health Journal, 37, 405-419. 